\title{
Teachers' Attitudes towards the Use of Instructional Resources in Teaching of the Novel
}

\author{
Rotumoi Joseph ${ }^{1} \&$ Lydia Cheruto Kipkoech ${ }^{2}$ \\ ${ }^{1}$ Department of Curriculum Instruction and Media, School of Education, University of Kabianga, Kenya \\ ${ }^{2}$ School of Education, University of Eldoret, Eldoret, Kenya \\ Correspondence: Lydia Cheruto Kipkoech, School of Education, University of Eldoret, P. O. Box 1125-30100, \\ Eldoret, Keny. E-mail: cherulk@yahoo.com
}

Received: May 8, 2013 Accepted: April 29, 2014 Online Published: August 29, 2014

doi:10.5539/ells.v4n3p58 URL: http://dx.doi.org/10.5539/ells.v4n3p58

\begin{abstract}
This study set out to investigate the varieties of instructional materials that are available and used for teaching the novel in selected secondary schools in Baringo District. The research was guided by Piaget's Cognitive Theory which has laid a strong case for the use of instructional media in instruction as it facilitates understanding of literary concepts and ideas. The study is a descriptive survey which was concerned with making accurate assessment of incidence, distribution and relationship of phenomena. Stratified random sampling was used to select the 12 secondary schools from which two form 3 and 4 literature teachers were selected to participate in this research. Descriptive data was collected by administering questionnaires and observing teachers during literature lessons. Evidence and deduction from data analysis revealed that most of the schools had some of the recommended novels but very few of the non-book instructional materials for teaching the subject. In addition, financial and administrative support was not easily obtainable and the novel was taught through verbal presentation. Recommendations are made with respect availability and use of instructional resources relevant for teaching the novel and the establishment of National and District instructional media Resource Centres.
\end{abstract}

Keywords: education, facilities, instruction, materials, novel, secondary

\section{Introduction}

The English language in Kenya plays an important role as a second language in school. Although Kiswahili is the national language, English language contributes to the broad national goals of education in all aspects in Kenya as it facilitates international cooperation. It is a compulsory subject on the national curricula at all levels of education except at the middle level colleges and higher institutions of learning. English is also used as the official language in Kenya. It was given this status through the Kenya Education Commission Report of 1965. English is preferred to other languages because of its access to higher learning, modern technology and international communication (Whiteley, 1973). English is thus important because in recent times, Kenya has become an international centre for services like agriculture, trade and technology that extends over the whole of East Africa and beyond. It plays the role of an international language.

Kenya has had a vague language policy that has not been clear on the languages to be used for instruction at various levels of schooling. During the colonial rule, there was a greater shift between vernaculars, Kiswahili and English regarding which language was to be used for instruction at various levels of schooling. For instance, the missionaries wanted the use of Kiswahili promoted in upper primary, 'gradually' being replaced by English. Gradually has no definite time - this would thus set time confusion as to when mother tongue should be dropped. In 1949, Kiswahili and English were taught as subjects while Kiswahili was used as a medium of instruction in lower primary up to primary four.

The language scenario in Kenya, being a multilingual country, exposes the learners and teachers to a certain range of languages from which they can make a choice to use what suits them most. Specifically, in the classroom setting, during instruction and learning Kiswahili, sheng and sometimes vernaculars take prominence over English. Though Kiswahili has undermined the role of English in schools, Barasa (1997) notes that, what has happened is that Kiswahili may have undermined the role of English in schools, with 
learners opting for Kiswahili where English remains a service language in the curriculum. English as the official medium of instruction in Kenyan secondary schools plays a central role in the entire secondary school curriculum.

Although the novel is like drama, poetry, the short story and oral literature, which deals with human experiences, its style is different. The novel is very well equipped for presenting the multitudeness of life Bradbury (1984) remarked that reading the novel is an individual's responsibility (private affair) and from a teaching point of view, it is important because of the individual experiences that count. It is with that in mind that it will partly form the basis of this study. The novel has an amalgam of incident, situation, dialogue, description and plenty of authorial intrusion or comment, which other genres cannot afford. Teaching the novel therefore is an individual experience. Historically, the novel is based on a literary tradition, mainly of western culture.

Although the general principles underlying literature teaching are valid for all development stages in the educational process, the appreciation of literature will not develop naturally, it must be taught, in the sense that the teacher must provide the most effective means of stimulating interest and promoting understanding (Tomlinson, 1989). Many pupils fail to develop sufficient proficiency to be able to enjoy good literature because texts must be read intelligently to be appreciated and understood. Teachers can overcome this obstacle to some extent by choosing simpler matter or by supplementing the pupils experience by using film and other audio-visual material on condition that it is able to connect it with a real life interests and pleasure.

One of the Kenya Institute of Education (KIE) prime function is that of preparing and approving instructional materials such as textbooks, media software, music equipment and tests among many others to accompany the syllabi to schools and colleges (Shiundu and Omulando 1992). These constitute a cross section of resources which aid the teacher in conveying knowledge and skills in the most effective manner. It is impossible to have meaningful teaching and learning in schools in the absence of their materials (Levy 1977). Lack of materials can hinder any programme from operating with desired efficiency (Mukwa 1993). He further observes that availability of necessary and relevant resources that are tools, facilities, equipment, personnel, finances and time are crucial in the successful implementation of any innovation. An innovation without supportive materials is likened to a farmer who goes to dig without relevant tools.

Kimani (1997) advocated for teaching approach where the learners would participate in the instructional process so that the learner would not depend entirely on the teacher for effective learning. Since then, emphasis laid on child-centred approach to teaching was moderated. This is because educators have realized that meaningful learning could only be achieved using learner-centred approach to teaching, which involves among other techniques use of Instructional media resources.

School text books and other Instructional materials play a in a child's learning and help to ensure the pupils receive the balanced and relevant curriculum to which they are entitled. It is the teacher's responsibility to utilise the books and materials in the classroom to their full potential in order to maximize the children's learning. Instructional resources are essential ingredients in learning and teaching the novel. When they are carefully selected and used by the teacher, students learn with a lot of ease and lead to improved results as Woodhall (1985).

The use of instructional resources such as textbooks among others is not a new phenomenon in teaching. Ayot et al (1984) recorded that students learn language more easily if instructional resources are well used. This shows that instructional resources have been utilized in teaching and learning for a long time.

Instructional resources are meant to help the teacher achieve his/her course objectives more effectively. Literature teachers should select the correct instructional resources that would enable the learner internalize, retain and use what has been learned effectively. However, the problem the teacher is likely to encounter in secondary schools is lack of a variety of instructional resources to teach the novel. Literature teachers can only make use of instructional resources when they are available, where teachers carefully avail, select and use instructional resources these objectives could be achieved. These observations are in agreement with what general educational communication technologists like Walkins (1982) and Mukwa (1988) have stated.

However there still exists an information gap concerning the availability and use of instructional resources for teaching the novel.. The present study aims at bridging this information gap. Hence, it is evident from the foregoing information that the role of instructional materials in the teaching of the novel cannot be underscored. This study sets out to ascertain the use and availability and instructional media in the teaching of the novel.

\section{Objectives of the Study}

The study sought to investigate teachers' attitudes towards the use of instructional resources used in teaching of 
the novel.

\section{Theoretical Framework}

This study was guided by the Piaget's 1964 theory of Cognitive Development, Beard (1980). Piaget's theory expounded by Wadsworth (1984), asserts that children's mental constructs are developed through their experiences in their environment. The theory holds that, the cognitive structure develops valiantly or sequentially and interactively forms the concrete to the more abstract one. In his theory, he specified four major stages of development:

- The sensor-motor stage - birth to about 2 years

- Pre-operational period - approximately 2 to 7 years

- Concrete-operational stage - seven up to eleven years

- Formal operational stage - twelve years onwards.

This study based its assumptions in the formal operational stage because most learners at form 3 and 4 fall in this stage.

\subsection{Formal Operations Stage}

Here, the child can use reasoning based on logic. He can formulate theories. The child is able to relate, differentiate, combine mentally and logically various ideas through symbols. Maximum ability at this stage is usually achieved through adulthood.

Piaget's theory implies that the child is not simply a passive organism that responds to any stimuli that occurs, but is an active organism. Piaget's theory implies that the activity of the child to learn more of the subject matter presented will increase as he progresses through the different stages of cognitive development. Therefore when a teacher decides to use learning resources of teaching, he has to take into account the learners' stages of cognitive development, if the learners are going to benefit from them. There is also the implication that some learning resources are better adapted than others in the presentation of subject content, to individuals of varying stages of cognitive development.

According to Piaget, cognitive re-organization resulting from assimilation and accommodation can come about only through actions of the child. Thus actions, physical or cognitive must occur if cognitive/re-organization is going to take place.

Piaget asserts that assimilation and accommodation of actions are always under internal control (Equilibration) and the re-organization of cognitive structures in a particular way, which can never be ensured by external organization of experience. Throughout the stage of concrete operations, the manipulation of objects and materials dealing with concepts to be learned is most important. During this stage, concrete experiences that result in reflective abstractions generate conceptual development (Wadsworth 1984)

Although Piaget was relating this theory to young children, it can as well be applied to the pupils at high school. Piaget argues that with the attainment of formal operations, children are able to develop some logical concepts without the aid of direct physical experience. However, conceptual development can proceed based on the child's actions on written and verbal materials. Even the adolescent or adult with preponderance for formal operations continue to use concrete experiences in the development of concepts. Hence, concrete experiences will still be needed in order to develop new physical knowledge.

This theory was applied to secondary school students because most of them are at the critical stage of learning new concepts, which are as challenging to them at their level (Form 3 and 4) and their new environment. Then, the theory lends itself well to the secondary school pupils who are experiencing literature that some teachers have claimed to be confusing. For instance, if one has never had any experience with sailboats, it is difficult to acquire any useful knowledge about them unless teaching aids are used.

Piaget's theory holds that experiences are necessary for intellectual development. Those experiences are to be organized in order to convey the required message. However, learning through experience is just one of the many ways through which knowledge is imparted. A pupil could still learn through either the discovery method or apprenticeship method among others. The theory emphasizes the importance and the need for instructional resources to enable students develop concepts and skills easily. This theory was applied in the present study on the basis of its function and utility in predicting behaviour as well as its persuasive power, logic and Novelty. It was on this ground that Piaget's theory continued to appeal as a guide to the present study of the availability and use of instructional resources by teachers. 
Piaget (1964) emphasizes throughout his work that cognitive and intellectual changes are the result of a developmental and coherent processes of successive qualitative changes of cognitive structure (Schemata). Each structure and its non-committant change derive logically and inevitably from the preceding one. The learning process starts at birth through primary education, where experiences are made vivid by use of concrete experiences, and when they join secondary school the process of learning should be made continuous as Piaget argues. In order for learning process to be continuous the use of instructional resources even for adults or adolescents in secondary school is essential. Piaget's theory was applied as a guide to this study since learning is a continuous process. The only difference being the complexity and level of the content covered at higher level.

\section{Methodology}

\subsection{Research Design}

This research was descriptive design, which was concerned with making accurate assessment of the incidence, distribution and relationship of phenomena. The data was collected by administering questionnaires. In the study, research questions and objectives were used. The data was analyzed and answers to the questions sought. The study aimed at getting accurate information about the characteristics of particular subjects, groups, institutions and situations about the availability and use of instructional media resources in the teaching of the novel. The descriptive analysis of data was used because of the nature of raw data that was collected and the research tools used. The research tools were mainly questionnaire - the likertscale, which is included in the questionnaire and an observational checklist suitable for a descriptive survey research design (Dalen 1979).

\subsection{Study Area}

The study was carried out in Baringo District. Baringo is one of the districts of Rift Valley Province. The district shares borders with nine other districts namely: Turkana and Samburu to the North, Laikipia to the East, Koibatek and Kericho to the South and UasinGishu, Keiyo, Marakwet and West Pokot to the West. The district provides an ample number of single sex schools, which the research used in the study. Secondly, there was hardly any research specifically dealing with the availability of instructional media in the teaching of the novel had been carried out in Baringo.

\subsection{Sampling Procedure}

At the time of study, there were 34 secondary schools in the district. According to Dale (1979) a sample between $10-30 \%$ of the total population is appropriate for study. Therefore the researcher used stratified random sampling and took $30 \%$ of the total population. This means that eleven secondary schools from which two formthree and form four teachers from each participating schools were chosen to take part in the study and in total there were twenty two teachers. It was thought form three and form four literature teachers have enough experience in teaching. Secondly, the novel is taught at form 3 and form 4 . However, one questionnaire went missing and the twenty one were analyzed.

\subsection{Data Collection Methods}

Before collecting data from the teachers the researcher first informed the head teachers and the head teacher brought it to the attentionof his teachers and it was my responsibility to personally establish a rapport with them. The researcher the questionnaire, delivered the research instruments, administered and collected them.

\subsection{Data Analysis Procedures}

The responses from the questionnaires were analyzed to show certain important aspects of the availability and use of instructional media resources in teaching the novel.These aspects included the availability of these resources in schools, the quality andtheir effectiveness in schools. Descriptive statistics were used to analyze the data. The specific descriptive statistics usedto analyze the data were: Frequency, percentages, mean and mode. Data were compiled in frequencies, and then converted into percentages and means. This information was presented into tabular form where appropriate in order to facilitate interpretation.

\section{Discussion of Findings}

The objective of this study was to investigate teachers' attitudes towards the use of instructional resources used in teaching the novel.

\subsection{Use of Instructional Materials in the Teaching of the Novel}

The following sub-section examines the use of instructional resources in the teaching of the novel in secondary school. Question item 2 sought to find out from the teachers who participated in this study, the books that they use to teach literature in general in order of priority. This study found out that Achebe's Aman of the People 
ranked on the chart followed closely by Imbuga's Aminata and Achebe's Things Fall Apart. Other texts mentioned include Amadi's The Concubine, Ngugi's The River Between, Sembene Osmane's God's Bits of Wood, Peter Abraham's Mine Boy, La Guma's A Walk in the Night, Ruganda's The Burdens, CamaraLaye's The African Child and Macgoye's Coming to Birth among others. This data revealed that most teachers were familiar with some of the relevant books for teaching the novel, though a few of the respondents are not aware of such books being relevant instructional resources.

\subsection{KIE Book Rating}

Question (3) sought to establish from literature teachers their opinion regarding the content and illustration of the Kenya Institute of Education (KIE) books. Analysis of datashow that 5(23.8\%) teachers reported that the rating is very good while $16(76.2 \%)$ said that was fairly good. Basing on this data, it can be deduced that KIE recommended books are cherished by the teachers and their attitude is positive with regard to content and language. This information is presented in the Table 1 below.

Table 1. Rating of Kenya Institute of Education texts

\begin{tabular}{ccc}
\hline KIE Book rating & Frequency & Percentage \\
\hline Very good & 5 & $23.8 \%$ \\
Fairly good & 16 & $76.2 \%$ \\
Inadequate & 0 & $0.0 \%$ \\
Do not know & 0 & $0.0 \%$ \\
Total & 21 & $100 \%$ \\
\hline
\end{tabular}

\subsection{Sources of Instructional Resources in Order of Priority}

Question item number 6 sought to find out from literature how they instructional resources they use for teaching the novel. The teachers' responses on the questionnaire were analysed and it revealed that $10(29.4 \%)$ teachers obtain instructional resources through a combination of the teachers and students making them; $5(14.7 \%)$ teachers obtain these resources through the effort of the 5(14.7\%) teachers secure these resources through collaboration by students and the school supplying them; finally, the study revealed that in the study area, there was no response to the effect that the ministry of Education science and technology instructional resources. Moreover the teachers did not give any other sources of these instructional materials.

Basing on this data, it can be deducedthat majority of the instructional resources used in schoolsarebought by schools and there 1:5 effort on the part of the students and teachers to supplement this effort. On the other hand, it is my considered opinion that there is an urgent need for the ministry to supply instructional materials as it does to primary schools following the decision by the NARC government to provide free education to all children of Kenya. The findings are presented in Table 2 below.

Table 2. Sources of instructional media resources for teaching the novel

\begin{tabular}{lcc}
\hline Sources of instructional resources & Frequency & Percentage \\
\hline (a). Students make them & 5 & $14.7 \%$ \\
(b). I make them & 8 & $23.5 \%$ \\
(c). The school buys them & 10 & $29.4 \%$ \\
(d). The ministry supplies & 0 & $0.0 \%$ \\
(e). A and B & 6 & $17.6 \%$ \\
(f). B and C & 5 & $14.7 \%$ \\
Total & 34 & $100.0 \%$ \\
\hline
\end{tabular}

\subsection{Statement of the Value of Instructional Media Resources in Teaching}

Question item number 12 of the questionnaire sought to establish teachers' perception about the availability and use of instructional media resources for teaching the novel. Nine statements were listed and each teacher was expected to tick one of the five levels of appreciation about each given statement. The statement given are all in the negative in the sense that they all show that there is no need of using instructional media resources in teaching the novel. The total number of responses was one hundred and eighty nine (189). 
Analysis and interpretation of data reveal that $8(4.2 \%)$ teachers responses strongly agreed (SA), $40(21.2 \%)$ teachers responses agreed (A), 4(2.1\%) responses indicated that they are undecided, $49(25.9 \%)$ show that teachers disagreed on the need to avail and use instructional media resources and finally $88(46.6 \%)$ teachers strongly disagree to the fact that there is need to avail media resources and use it appropriately.

\subsection{Literature Teachers' Interest in Using Instructional Resources}

To assess whether literature teachers are interested in using instructional resources in teaching the novel, question item number 14 of the questionnaire investigated the individual teachers' interest in using instructional resources in teaching the novel. The analysis of data reveals that no single teacher strongly agreed, agreed and undecided. 4(19.0\%) teachers disagreed with the statement that teachers are not interested in using instructional materials and 17(81.0\%) teachers disagreed. This showed that all the 21(100.0\%) teachers were interested in using instructional resources for the teaching of the novel. This implies that all the teachers who participated in this study are aware of the importance of instructional resources. The high rate of agreement shows that teachers strongly agree that use of instructional resources makes learning effective for both the learner and the teacher. Surprisingly, teachers agree with the statement but rarely use a variety of the available resources other than the chalkboard and recommended text. On the whole, it shows that teachers have a positive attitude towards the use of instructional resources.

\subsection{Finance as a Constraint}

Question item number 15 sought to find out from teachers whether financial constraint could be a major reason that inhibits them from availing and using instructional resources in teaching the novel. Analysis of the data show that 5(23.8\%) teachers strongly agreed, $10(47.6 \%)$ teachers agreed, $3(14.3 \%)$ teachers disagreed. This information indicates that $15(71.4 \%)$ teachers are of the opinion that money is a constraint when it comes to availing instructional resources for teaching the novel. Therefore there is need to avail funds to purchase some of the resources but others have to be inevitably improvised by teachers.

\subsection{Value of Text Books}

Question item number 16 sought to establish the value of text books in general in teaching literature. Analysis of the data show that $14(66.7 \%)$ teachers strongly agreed, $7(33.3 \%)$ teachers agreed. There were responses for undecided, disagree and strongly disagree. This shows that all the teachers who participated in this study hold the view that text books are indispensable tools in the learning process and should be availed in abundance to learning institutions.

\section{Conclusion}

Basing on these findings, it can be concluded that the teachers use the available instructional resources for teaching the novel. What was not clear was whether these teachers could use the instructional resources satisfactorily. This could be attributed to the training the teachers received because the research study revealed that there had never been any in-service course or seminar where the use of instructional media resources in the teaching of the novel had been emphasized.

\section{Recommendations}

1) Findings of the study suggest that teachers of literature be sensitized on lesson allocation. The office of Quality Assurance and Standards Office should come up with a clear policy on the number of lessons devoted to each genre of literature namely: the novel, the play, short story, oral literature and poetry. Teachers should endeavor to ensure time is valued and time allocated for the novel is fully utilized.

2) The teachers' attitude towards the use of instructional media is positive hence, there is need for more effort to be made to produce, purchase and avail a variety of instructional resources for teachers to easily obtain and select the relevant for use during literature lessons.

\section{References}

Ayot, H. O. et al. (Eds). (1984). Language for Learning. Nairobi: Macmillan Kenya Limited.

Barasa, L. P. (1997). English Language Teaching in Kenya Secondary Schools Policy Planning and Practice (Unpublished thesis). University of Hull.

Beard, R. M. (1980). An Outline of Piagets Developmental Psychology. London: Routledge Kogan Page.

Bradbury, J., Lewis, R. B., \& Harccleroad, F. (1985). A.V Mstruction.Technology Media and Methods. Singapore: MacGraw-Hill Book Lewis R.B. Co.

Dale, D. B. V. (1979). Understanding Educational Research: An Introduction. New York: McGraw-Hill Inc. 
Dalen, E. (1954). Audio-Visual Methods in Teaching. New York: The Drydgen Press.

Kenya Institute of Education (KIE). (1992). Secondary Education Syllabus. Nairobi: Ministry of Education.

Kenya Institute of Education. (1987). A Handbook for Teachers of English in Secondary Schools in Kenya. Nairobi: Jomo Kenyatta Foundation.

Mukwa, C. W. (1979). Towards a Systematic Approach to Educational Media Use in the Secondary School education of the Republic of Kenya: A Field Survey of Tools and Technologies for learning (Unpublished master's thesis). U.S.: Michigan State University.

Republic of Kenya. (1964). Kenya Education commission Report. Nairobi: (Ominde Report) Government Press.

Shiundu, J. S., \& Omulando, S. J. (1992). Curriculum theory and Practice in Kenya. Nairobi: Oxford University Press.

Tolimson, A. (1989). Teaching English as a Second Language. London: Kogan Page Ltd.

Wadsworth, B. J. (1984). Piagets Theory of Cognitive and Affective Development. New York: Longman.

Walkin, D. (1982). Instructional Techniques and Practice. England: Stanley Thornes Publishers Ltd.

Whiley, W. H. (Ed.). (1974). Language in Kenya. Nairobi: Oxford University Press.

\section{Copyrights}

Copyright for this articleis retained by the author(s), with first publication rights granted to the journal.

This is an open-access article distributed under the terms and conditions of the CreativeCommons Attribution license (http://creativecommons.org/licenses/by/3.0/). 